a researcher or academic, and it would be unfortunate to see well-trained older individuals leave their positions while they remain enthusiastic and productive. Encouraging universities and research institutes to make full use of the human resources that are available benefits both science and society. That is especially true in developing countries, where intellectual resources are in short supply yet in high demand.

Statistics on age distribution in the scientific community are even more limited than those on gender distribution, and data are particularly sparse in the developing world.

\section{GENERATION NEXT}

As part of a larger demographic trend, the developed world is facing a future marked by ageing researchers and faculty. Improvements in medical care, combined with laws prohibiting mandatory retirement, have led a growing number of researchers and academics to continue working well beyond their sixties or even seventies. Statistics show that there was a threefold increase in the number of faculty over 70 years of age in US universities between 1995 and 2000. As Lawrence Summers, former president of Harvard University, has noted: "It defies belief that the best way to advance creative thought, to educate the young, or to choose the next generation of faculty members is to have a tenured faculty with more people over 70 than under 40".

In India, by way of contrast, faculty must retire by the age of 60 years. As a result, the 'greying' of academia is not as much an issue there as it is in developed countries. India's slow promotion system, which at times is based more on personal contacts than merit, elicits much more concern and many more complaints.
While systems of promotion vary across the developing world, many still follow outdated methods of assessment drawn from the colonial period. However, many countries in the develop ing world have undergone a rapid expansion in higher education that has required them to hire a large number of young professors. In China, for example, $30 \%$ of the faculty are in their twenties and thirties, while only $3 \%$ are older than 60 years. There is, however, a 'faculty void' between the ages of 45 and 50 years, largely due to the assault on science and other intellectual pursuits that took place during the Cultural Revolution.

In 1990, an estimated 68 million students were attending universities worldwide. In 2004, the world's student population had nearly doubled to 132 million, and by 2025 it is projected to reach 150 million. Most of this growth is taking place in developing countries.

More students, of course, means more faculty will be needed. Yet, universities and publicly funded research institutes are not the only places where scientists and scholars can be found. There is also a rising number of research and development centres in the private sector, eagerly seeking to hire young graduates with good analytical skills. This is true in both the developed and the developing world.

In short, age is an issue in science and academia across the globe. But the developing world's youthful population, combined with the unprecedented growth of universities and research centres, could mean that young scientists and academics will enjoy greater opportunities for advancement than their counterparts in the developed world. That will be true, however, only if procedures for hiring

\section{VIEWPOINT I Zohra Ben Lakhdar-Akrout More than good enough to do world-class research}

When I returned to Tunisia from France in the late 1970s, my country's scientific capacity was low. Scant government investment in science and technology reflected that reality. The laboratory where I worked had no equipment and a staff of one. Today, my laboratory is staffed by 50 scientists and equipped with two lasers: a diode laser that arrived in 1995, with financial help from the European Union; and a nanosecond pulsed laser, which was paid for by the Tunisian government and began operation in 2003. We might not have a faster, more powerful (and, I might add, more expensive) femtosecond pulsed laser, often found in laboratories in developed countries. Yet, our equipment is good enough as it is to do world-class research. The laboratory has an annual budget of around US\$100,000. That is by no means lavish. But it allows us to buy equipment, fund graduate students, have our researchers participate in international workshops and have other scientists visit our laboratories. In the 1980s, funds were so meagre that I had to focus on theoretical studies of the interaction of atoms and molecules. There was no way I could afford to do experimental research. Research was so difficult that it took me 10 years to publish my first paper. Today, thankfully, there is growing awareness among the nation's political leaders that science is a key to development and a fundamental prerequisite for growth.

Zohra Ben Lakhdar-Akrout (TWAS Fellow 2006) is director of the Laboratory of Atomic-Molecular Spectroscopy and Applications at the University of Tunis in Tunisia. and advancement become less cumbersome and easier to implement. The young will be present in the developing world in large numbers, but whether they will be well-served will depend as much on administrative reforms as on demographics.

\section{WHERE TO NOW?}

As the discussion above indicates, issues related to gender and age are complex and multifaceted. Perceptions might differ from reality, and solutions might be less evident than they first appear.

This is particularly true in the case of gender distribution, where historical and societal forces have moulded cultural values that are not easily altered.

Attaining full gender equality, whether in science, academia or other sectors of society, will require a profound transformation in cultural values that will take generations to achieve. While waiting for a cultural revolution that might never arrive, nations could embark on specific reform measures to mitigate the problems inherent in the gender and age gaps. The measures that they might want to consider include educational programmes to increase awareness of the importance of gender equity both as a moral and economic issue. It could also mean enacting policies that encourage women to pursue education and employment in fields of science and scholarship.

Developing countries have a great deal to gain from the full participation of women in the knowledge economy. It is encouraging to note that many developing countries enjoy a head start in their efforts to advance this goal, largely due to the comparatively high percentage of professional women found in elite, high-paying fields. The challenges today lie in increasing opportunities for poorer, less-educated women in cities, small villages and rural areas, and in breaking through the 'glass ceiling' so that more women will hold management and leadership positions.

As for age imbalances, innovative policies must be devised to protect experienced knowledge workers without discouraging the next generation of students from entering science and other fields. For example, older professors could be allowed to remain on the faculty without remuneration and without administrative responsibilities - allowing them to pursue their own research agendas freely and to teach classes. This would allow older faculty to remain active and involved without blocking the career paths of younger researchers. It would also encourage an intergenerational exchange of ideas and research collaborations between young and old. It does, of course, depend on having reasonable pension systems in place, and a willingness to approve and enforce mandatory rules for retirement.

Achieving gender equality and constructing a balanced age profile in the developing world

Çiğdem Kağıtçıbaşı (TWAS Fellow 2006) is a professo of psychology at Koc University in Istanbul, Turkey. 